\title{
Neurological palliative care — who, how, when?
}

\author{
Abstract \\ There is increasing collaboration between palliative care and neurology, intending to improve the quality \\ of care and quality of life of people with neurological disease and their families. \\ Palliat Med Pract 2020; 14, 2: 75-77 \\ Key words: palliative care, neurology, collaboration
}

Palliative care is often associated with the care of people with cancer, but as the World Health Organisation definition talks of "patients and their families facing problems associated with life-threatening illness" many other disease groups, including people with the neurological disease should be considered for palliative care [1]. This has been reinforced by the development of guidelines for neurological palliative care and increasing evidence for the effectiveness of this approach. The European Academy of Neurology and the European Association for Palliative Care have developed a Consensus document on palliative care for patients with the chronic and progressive neurological disease [2]. This makes several recommendations, although the supporting evidence is often limited. These are relevant to all involved in the care of neurological patients - both neurologists and palliative care specialists.

Palliative care is recommended to be integrated early in the care of people with neurological disease. There is evidence from cancer care that early palliative care may lengthen survival and reduce hospital care [3] and a meta-analysis of studies on home palliative care concluded that patients were more likely to die at home and symptom burden was reduced [4]. Within neurological care, early involvement, by a short intervention service for people with multiple sclerosis
(MS), improved symptoms, reduced caregiver burden and was cost-effective [5, 6]. A randomised trial of palliative care team involvement showed improvement in the quality of life and improvement in the symptoms of sleep, pain, bowel problems and breathlessness [7].

Thus, there is increasing evidence for palliative care being effective for neurological patients and palliative care is now included in the guidelines for many neurological diseases including motor neurone disease/amyotrophic lateral sclerosis (MND/ALS) [8], Parkinson's disease (PD) [9] and MS [10]. The role of the multidisciplinary team in neurological care has been emphasised in these guidelines and the Consensus document. Two studies have shown that an MDT approach for MND/ALS may improve survival [11, 12] and a study in MS showed increased satisfaction with MDT [5]. Palliative care is increasingly seen as an important part of the MDT, and enables liaison with specialist palliative care services.

The care of people with progressive disease requires a clear approach in the communication of the issues, and hearing the concerns of the patients and families, and setting clear goals for care. This starts at the diagnosis and it is important to ensure that this is communicated effectively and with empathy [13]. The discussion of the future is important throughout the disease progression and this will include planning.

Address for correspondence:

David John Oliver

Tizard Centre, Cornwallis North East, University of Kent, Canterbury, Kent CT2 4NF, United Kingdom

e-mail: drdjoliver@gmail.com

Palliative Medicine in Practice 2020; 14, 2, 75-77

Copyright (c) Via Medica, ISSN 2545-0425

DOI: 10.5603/PMPI.2020.0016 
Advance care planning, when a person expresses their views on future care while they can do so so that these are known if they lose capacity and are unable to make the decision themselves, is very important for people with neurological disease, many of whom will lose communication or cognitive ability [14].

The management of symptoms may be complex in neurological disease, with many patients having multiple and difficult issues, including pain, dysphagia, dysarthria, breathlessness, drooling, and psychological issues, such as anxiety or depression. This may require expertise in palliative care and increasingly neurologists are gaining these skills and undertaking this care [15]. For some issues, which are more complex, specialist palliative care services may become involved, using their increased expertise, training and MDT approach [16].

Most people with the neurological disease are part of larger social groups, usually families, who face their own issues in caring for the person and extra support is helpful, both as the patient deteriorates and after death in bereavement. This support should be available from all members of the MDT, with specific psychological support available. The professional team may also be helped by support and supervision, as they face continual deterioration and the loss of their patients [2].

As patients approach the end of life the need for palliative care may be greater. However, there is increasing evidence that palliative care may be appropriate at any time during the disease progression, this should depend on the issues and needs of the patient and family, rather than a specific prognosis [2]. Discussion about the concerns of end of life - symptoms that are feared, such as pain, breathlessness or distress, the care of family or carers or the wish to discuss hastening death - may be discussed at any time. It has been suggested that soon after diagnosis and when new interventions are commenced would be opportunities to encourage discussion of the future, listening to the concerns of the person and discussing future care options, including advance care planning [8].

As the end of life approaches it is important to anticipate possible deterioration and ensure that all involved are aware of the future needs. Discussion with the person, if possible, the family and the carers is important and it is helpful to ensure that medication to cope with a sudden deterioration and distress is available, so that it can be given without delay [17]. According to the legalisation in each country, discussion of the role of resuscitation, hospitalisation and treatment at the end of life is important. Patients and families may wish to discuss a hastened death - either euthanasia or physician-assisted dying [18] — and opportunities should be given for these discussions, even if there is no legalised option for hastened death within the country [2]. The concerns behind such requests may be discussed, and, on occasions, explanation and reassurance of symptom management, care and support at the end of life may reduce the wish for hastened death [19].

Palliative care is complex and may be considered at several levels. All professionals should provide good basic palliative care approach — good communication, shared decision making and goal setting and symptom management. Neurology services and primary care may provide general palliative care, with some extra training and for the complex issues specialist palliative care services are available in most areas to support the complex assessment and management of symptoms and other issues - psychosocial and spiritual $[16,20]$. Increasingly neurologists are providing ongoing care to patients and are gaining the expertise to manage many issues $[15,20]$. They will continue to seek palliative care education, and palliative care specialists and services will need to develop their knowledge of the particular issues for neurology patients. A recent survey in Europe showed that there is often collaboration for people with cerebral tumour and MND/ALS but less for other neurological diseases [21].

Over the coming years, there may be an increasing collaboration between neurology and palliative care so that people with neurological disease, and their families, may have as good a quality of life as possible and can die peacefully.

\section{Conflict of interests}

The author declares no conflict of interest.

Funding

This study has no funding.

\section{References}

1. World Health Organization. (2002). Palliative care. http:// www.who.int/cancer/palliative/definition/en/.

2. Oliver DJ, Borasio GD, Caraceni A, et al. A consensus review on the development of palliative care for patients with chronic and progressive neurological disease. Eur J Neurol. 2016; 23(1): 30-38, doi: 10.1111/ene.12889, indexed in Pubmed: 26423203.

3. Temel JS, Greer JA, Muzikansky A, et al. Early palliative care for patients with metastatic non-small-cell lung cancer. N Engl J Med. 2010; 363(8): 733-742, doi: 10.1056/NEJMoa1000678, indexed in Pubmed: 20818875.

4. Gomes B, Calanzani N, Curiale V, et al. Effectiveness and cost-effectiveness of home palliative care services for adults with advanced illness and their caregivers. Cochrane Database Syst Rev. 2013(6): CD007760, doi: 10.1002/14651858. CD007760. pub2, indexed in Pubmed: 23744578.

5. Edmonds P, Hart S, Vivat B, et al. Palliative care for people severely affected by multiple sclerosis: evaluation of a novel 
palliative care service. Mult Scler. 2010; 16(5): 627-636, doi: 10.1177/1352458510364632, indexed in Pubmed: 20305044.

6. Higginson IJ, McCrone P, Hart SR, et al. Is short-term palliative care cost-effective in multiple sclerosis? A randomized phase II trial. J Pain Symptom Manage. 2009; 38(6): 816-826, doi: 10.1016/j.jpainsymman.2009.07.002, indexed in Pubmed: 19833477.

7. Veronese $S$, Gallo $G$, Valle A, et al. Specialist palliative care improves the quality of life in advanced neurodegenerative disorders: NE-PAL, a pilot randomised controlled study. BMJ Support Palliat Care. 2017; 7(2): 164-172, doi: 10.1136/bmjspcare-2014-000788, indexed in Pubmed: 26182947.

8. National Institute for Health and Care Excellence. NICE Guidance on Motor Neurone Disease. 2016. NICE. http:// www. nice.org.uk/NG42.

9. National Institute for Health and Care Excellence Parkinson's disease in adults. 2017. https://www. nice.org. uk/guidance/ng71.

10. Solari A, Giordano A, Sastre-Garriga J, et al. guideline task force, guideline task force. EAN guideline on palliative care of people with severe, progressive multiple sclerosis. Eur J Neurol. 2020 [Epub ahead of print], doi: 10.1111/ene.14248, indexed in Pubmed: 32469447.

11. Aridegbe $\mathrm{T}$, Kandler R, Walters $\mathrm{SJ}$, et al. The natural history of motor neuron disease: assessing the impact of specialist care. Amyotroph Lateral Scler Frontotemporal Degener. 2013; 14(1): 13-19, doi: 10.3109/17482968.2012.690419, indexed in Pubmed: 22642305.

12. Rooney J, Byrne $\mathrm{S}$, Heverin $\mathrm{M}$, et al. A multidisciplinary clinic approach improves survival in ALS: a comparative study of ALS in Ireland and Northern Ireland. J Neurol Neurosurg Psychiatry. 2015; 86(5): 496-501, doi: 10.1136/jnnp-2014309601, indexed in Pubmed: 25550416.

13. Aoun SM, Breen $U$, Howting $D$, et al. Receiving the news of a diagnosis of motor neuron disease: What does it take to make it better? Amyotroph Lateral Scler
Frontotemporal Degener. 2016; 17(3-4): 168-178, doi: 10.3109/21678421.2015.1111907, indexed in Pubmed: 26609553.

14. Chapman S. Advance Care planning. In: Oliver D. ed. End of life care in neurological disease. Springer, London 2013: 133-142.

15. Robinson MT, Holloway RG, Robinson MT, et al. Palliative Care in Neurology. Mayo Clin Proc. 2017; 92(10): 1592-1601, doi: 10.1016/j.mayocp.2017.08.003, indexed in Pubmed: 28982489.

16. Radbruch L, Payne S, Radbruch L, et al. White Paper on standards and norms for hospice and palliative care in Europe: part 1. Eur J Palliat Care. 2009; 16: 278-289.

17. Bowers $B$, Ryan R, Kuhn I, et al. Anticipatory prescribing of injectable medications for adults at the end of life in the community: A systematic literature review and narrative synthesis. Palliat Med. 2019; 33(2): 160-177, doi: 10.1177/0269216318815796, indexed in Pubmed: 30513254.

18. Radbruch L, Leget $C$, Bahr $P$, et al. Board Members of EAPC, Board Members of EAPC. Euthanasia and physician-assisted suicide: A white paper from the European Association for Palliative Care. Palliat Med. 2016; 30(2): 104-116, doi: 10.1177/0269216315616524, indexed in Pubmed: 26586603.

19. Connolly S, Galvin M, Hardiman O, et al. End-of-life management in patients with amyotrophic lateral sclerosis. The Lancet Neurology. 2015; 14(4): 435-442, doi: 10.1016/s1474-4422(14)70221-2.

20. Creutzfeldt CJ, Robinson MT, Holloway RG, et al. Neurologists as primary palliative care providers: Communication and practice approaches. Neurol Clin Pract. 2016; 6(1): 40-48, doi: 10.1212/CPJ.0000000000000213, indexed in Pubmed: 26918202.

21. Oliver D, Hepgul N, Borasio GD, et al. Collaboration between neurology and palliative care; a European survey. Poster at the 5th European Academy of Neurology Congress, Oslo. June 2019. 


\section{Opieka paliatywna dla pacjentów ze schorzeniami neurologicznymi — dla kogo, jak, kiedy?}

Artykuł jest tłumaczeniem pracy: Oliver D.J., Neurological palliative care - who, how, when? Palliat. Med. Pract. 2020 tom 14, nr 2: 75-77.

Należy cytować wersję pierwotną.

Piśmiennictwo znajduje się na stronach 76-77.

Streszczenie
Współpraca pomiędzy opieką paliatywną a neurologią, mająca na celu poprawę jakości życia osób z cho-
robami neurologicznymi oraz ich rodzin, jest coraz ściślejsza. Palliat Med Pract 2020; 14, 2: 78-80

Słowa kluczowe: opieka paliatywna, neurologia, współpraca

Opieka paliatywna często wiąże się z opieką nad pacjentami z chorobą nowotworową, ale ponieważ definicja Światowej Organizacji Zdrowia (WHO, World Health Organization) mówi o "chorych i ich rodzinach borykających się z problemami związanymi z zagrażającą życiu postępującą chorobą", wiele innych grup chorób, w tym choroby neurologiczne, powinno zostać uwzględnionych w ramach opieki paliatywnej [1]. Fakt ten znalazł potwierdzenie w opracowaniu wytycznych dotyczących opieki paliatywnej nad pacjentami ze schorzeniami neurologicznymi oraz w rosnącej liczbie dowodów na skuteczność tego podejścia. Europejska Akademia Neurologii i Europejskie Towarzystwo Opieki Paliatywnej opracowały dokument w sprawie konsensusu dotyczącego opieki paliatywnej nad chorymi z przewlekłą i postępującą chorobą neurologiczną [2]. Zwiera on szereg zaleceń, chociaż dowody na ich poparcie są często ograniczone. Zalecenia te są istotne dla wszystkich osób zaangażowanych w opiekę nad pacjentami ze schorzeniami neurologicznymi, zarówno neurologów, jak i specjalistów opieki paliatywnej.

Zaleca się włączenie opieki paliatywnej do terapii osób z chorobami neurologicznymi na wczesnym etapie. Istnieją dowody potwierdzające, że wczesne objęcie chorych opieką paliatywną może wydłużyć ich życie i zredukować konieczność opieki szpitalnej [3], a z metaanalizy badań nad domową opieką paliatywną wynika, że chorzy częściej umierają w domu, a obciążenie wieloma objawami zmniejsza się [4]. W ramach opieki neurologicznej wczesne włączenie opieki paliatywnej, w postaci krótkiej interwencji dla osób ze stwardnieniem rozsianym (SM, sclerosis multiplex), wpłynęło na objawy podmiotowe, zmniejszenie obciążenia opiekunów i było racjonalne pod względem kosztów [5, 6]. Randomizowane badanie zaangażowania zespołu opieki paliatywnej wykazało polepszenie jakości życia i poprawę w zakresie objawów związanych ze snem, bólem, zaburzeniami jelitowymi i dusznością [7].

\section{Adres do korespondencji:}

David John Oliver

Tizard Centre, Cornwallis North East, University of Kent, Canterbury, Kent CT2 4NF, Zjednoczone Królestwo

e-mail: drdjoliver@gmail.com 
Tym samym istnieje coraz większa liczba dowodów na skuteczność opieki paliatywnej u chorych ze schorzeniami neurologicznymi, a opieka paliatywna jest obecnie uwzględniona w wytycznych dotyczących wielu chorób neurologicznych, w tym choroby neuronu ruchowego/stwardnienia zanikowego bocznego (MND/ALS, motor neurone disease/amyotrophic lateral sclerosis) [8], choroby Parkinsona (PD, Parkinson's disease) [9] i SM [10]. Wytyczne te, a także dokument $\mathrm{w}$ sprawie konsensusu, podkreślają rolę multidyscyplinarnego zespołu (MDT, multidisciplinary team) w opiece nad pacjentami ze schorzeniami neurologicznymi. Wyniki dwóch badań wykazały, że wykorzystanie MDT w przypadku MND/ALS może zwiększyć przeżywalność [11, 12], a badanie przeprowadzone u pacjentów z SM wykazato wzrost zadowolenia z MDT [5]. Opieka paliatywna jest coraz częściej postrzegana jako ważny element MDT, umożliwiający współpracę ze specjalistycznymi zespołami opieki paliatywnej.

Opieka nad osobami z postępującą chorobą wymaga jasnego komunikowania wszelkich kwestii oraz zrozumienia obaw pacjentów i ich rodzin, a także wyznaczenia wyraźnych celów w zakresie opieki. Proces ten rozpoczyna się $w$ momencie postawienia diagnozy i już wtedy ważne jest zapewnienie skutecznej i pełnej empatii komunikacji [13]. Rozmowy na temat przyszłości są istotne przez cały okres rozwoju choroby i obejmują one również planowanie długoterminowe. Planowanie opieki z wyprzedzeniem, kiedy osoba wyraża swoją opinię na temat przyszłej opieki, gdy jest jeszcze w stanie to zrobić, jest niezwykle istotne dla osób cierpiących na choroby neurologiczne, z których wiele straci zdolność komunikacji lub zdolności poznawcze [14].

Leczenie objawów może być skomplikowane w przypadku chorób neurologicznych, u wielu pacjentów występują liczne i trudne do opanowania dolegliwości, w tym ból, dysfagia, dyzartria, duszność, ślinotok, a także problemy psychologiczne, takie jak lęk czy depresja. Nierzadko wymagają one posiadania specjalistycznej wiedzy z zakresu opieki paliatywnej, którą coraz częściej nabywają neurologowie i decydują się na podjęcie tego rodzaju opieki [15]. W przypadku niektórych, bardziej złożonych kwestii, możliwe jest włączenie specjalistycznych usług opieki paliatywnej, czerpiąc z ich wysokiej wiedzy specjalistycznej, szkoleń i podejścia wykorzystującego MDT [16].

Najczęściej osoby z chorobami neurologicznymi stanowią część większych grup społecznych, zazwyczaj rodzin, które borykają się z własnymi problemami w opiece nad tą osobą, a dodatkowe wsparcie jest niezwykle istotne, zarówno w sytuacji pogorszenia się stanu zdrowia chorego, jak i po jego śmierci, w okresie żałoby. Wsparcie to powinno być dostępne ze strony wszystkich członków MDT, przy zapewnieniu szczególnej pomocy psychologicznej. Ważne jest, aby zespół specjalistów również miał możliwość uzyskania pomocy w postaci wsparcia i nadzoru, ponieważ są to osoby nieustannie doświadczające pogorszenia stanu zdrowia i śmierci swoich pacjentów [2].

Wobec zbliżającego się kresu życia chorego, zapotrzebowanie na opiekę paliatywną może być większe. Istnieje jednak coraz więcej dowodów na to, że opieka paliatywna może być konieczna w każdym momencie rozwoju choroby, co powinno być uzależnione od dolegliwości oraz potrzeb chorego i jego rodziny, a nie od określonego rokowania [2]. Rozmowa o obawach związanych z kończącym się życiem - kwestiach, które budzą lęk, takie jak ból, duszności lub niepokój, o opiece rodziny lub opiekunów albo chęci omówienia przyspieszenia śmierci - może być przeprowadzona w każdej chwili. Zasugerowano, że wkrótce po postawieniu diagnozy i wdrożeniu nowych działań, można zachęcić pacjenta do rozmów na temat przyszłości, wysłuchać jego obaw i omówić opcje oraz zaplanować przyszłą opiekę [8].

Wraz ze zbliżaniem się kresu życia ważne jest, aby uprzedzić o ewentualnym pogorszeniu się sytuacji i upewnić się, że wszyscy zainteresowani są świadomi swoich przyszłych potrzeb. Rozmowa z pacjentem oraz, jeśli to możliwe, z rodziną i opiekunami, jest ważna i pomaga zapewnić dostępność leków na wypadek nagłego pogorszenia się stanu zdrowia i wyczerpania chorego tak, aby można je było podać bez zbędnej zwłoki [17]. Omówienie roli reanimacji, hospitalizacji i leczenia pacjentów u schyłku życia jest istotne $z$ punktu widzenia obowiązującego $w$ każdym kraju ustawodawstwa. Pacjenci oraz członkowie ich rodzin mogą wyrazić chęć przedyskutowania kwestii przyspieszonej śmierci - zarówno eutanazji, jak i samobójstwa wspomaganego przez lekarza [18] —i należy dać im możliwość podjęcia takiej rozmowy, nawet jeśli w danym kraju nie istnieje żadna prawnie dozwolona możliwość przyspieszenia śmierci [2]. Obawy towarzyszące takim prośbom mogą być przedmiotem rozmów, a w niektórych przypadkach odpowiednie wyjaśnienie i zagwarantowanie leczenia objawów, opieki i wsparcia u schyłku życia może zmniejszyć pragnienie przyspieszonej śmierci [19].

Opieka paliatywna jest złożonym zagadnieniem i może być rozpatrywana na kilku płaszczyznach. Wszyscy specjaliści powinni zadbać o odpowiednie podejście do podstawowej opieki paliatywnej - dobrą komunikację, wspólne podejmowanie decyzji, wyznaczanie celów i leczenie objawów. Neurologia i podstawowa opieka paliatywna mogą świadczyć pomoc w zakresie ogólnej opieki paliatywnej, po odbyciu przez nich dodatkowego szkolenia, zaś w przypadku 
złożonych dolegliwości w większości dziedzin dostępna jest specjalistyczna opieka paliatywna wspierająca kompleksową ocenę i leczenie objawów oraz podejmowanie innych kwestii - psychospołecznych czy duchowych [16, 20]. Neurologowie coraz częściej sprawują stałą opiekę nad pacjentami, zdobywając tym samym doświadczenie $w$ radzeniu sobie $z$ wieloma wyzwaniami $[15,20]$. W dalszym ciągu będą oni poszukiwać możliwości kształcenia w zakresie opieki paliatywnej, a specjaliści i usługi z zakresu opieki paliatywnej będą musieli pogłębiać swoją wiedzę na temat poszczególnych kwestii dotyczących pacjentów ze schorzeniami neurologicznymi. Ostatnie badanie przeprowadzone w Europie wykazało, że często do- chodzi do współpracy w przypadku osób z guzem mózgu i MND/ALS, ale rzadziej ma to miejsce przy pozostałych chorobach neurologicznych [21].

W nadchodzących latach może nastąpić zacieśnienie współpracy między neurologią a opieką paliatywną tak, aby zarówno pacjenci cierpiący na choroby neurologiczne, jak i ich rodziny miały zapewnioną możliwie dobrą jakość życia i mogły umrzeć w spokoju.

\section{Konflikt interesów}

Autor deklaruje brak konfliktu interesów.

\section{Finansowanie}

Badanie nie było finansowane. 